\title{
Derleme/Review \\ Türkiye ve Avrupa Birliği Ülkelerinin Sebze Üretimi ve Kendine Yeterlilik Bakımından Karşılaştırılması
}

\author{
İsmail GÜVENÇ* \\ KSÜ Ziraat Fakültesi Bahçe Bitkileri Bölümü, Avşar Kampüsü, Kahramanmaraş, Türkiye \\ * e-posta: ismailguvenc@ksu.edu.tr, tel: 03442802064
}

\begin{abstract}
Öz: Bu çalışmada Türkiye ve AB'de toplam sebze üretimi, sebze üretiminin sebze türlerine dağılımı, AB'de sebze üretiminin ülkelere dağılımı ve sebzelerde yeterlilik durumu incelenmiştir. 2016 verilerine göre Türkiye'de 30.1 ve AB'de 69.2 milyon ton civarında sebze üretilmiştir. Türkiye'de sebze üretiminin \% 82.5'ni domates, biber, patlıcan, kavun ve karpuz gibi meyvesi yenilen sebzeler oluşturmaktadır. Toplam sebze üretiminin yaklaşık olarak \% 40-45'ini domates oluşturmaktadır. $\mathrm{AB}$ ülkelerinde ise yaprak ve yumruları yenilen sebzeler üretimde daha yüksek paya sahiptir. AB sebze üretiminin \% 65-70'i 7 üye ülkede gerçekleştirilmektedir. Bu ülkeler İtalya (\% 21.3), İspanya (\% 18.7), Polonya (\% 8.5), Fransa (\% 7.5), Hollanda (\% 7.2), Almanya (\% 5.4) ve Yunanistan’dır (\% 5.3). Türkiye’nin sebze üretiminde kendine yeterliliği $\mathrm{AB}$ ülkelerinin kendine yeterliliğinden daha yüksektir.
\end{abstract}

Anahtar kelimeler: Avrupa Birliği (AB), Sebzeler, Sebze üretimi, Türkiye, Yeterlilik

\section{Vegetables Production and Self-Sufficiency in Turkey and the European Union (EU)}

\begin{abstract}
In this study, it was evaluated the total vegetables production, distribution of production to vegetable species, and self-sufficiency of vegetables production in Turkey and the European Union (EU), and share of countries in vegetable production in EU. According to 2016 data, vegetables were produced as 30.1 million tons in Turkey and 69.2 million tons in EU. The vegetables' production of Turkey largely consists of fruit vegetables (82.5\%) such as tomatoes, peppers, eggplants, melons and watermelons. Tomatoes have approximately a share in $40-45 \%$ of total vegetable production of Turkey. On the other hand, the share of leafy and tuber vegetables in vegetable production of EU countries is higher than that of Turkey. Most (65-70\%) of the vegetable in the EU is produced in 7 member countries. These countries are Italy (21.3\%), Spain (18.7\%), Poland (8.5\%), France (7.5\%), Netherlands (7.2\%) and Greece (5.3\%). Turkey's self-sufficiency in vegetable production is higher than that of EU countries.
\end{abstract}

Key words: The European Union (EU), Vegetable, Vegetables production, Turkey, Sufficiency

\section{Giriș}

Avrupa Birliği (AB) 28 üye ülkeden oluşmaktadır. Birlik kurulduğu günden beri izlenen ortak tarım politikaları ile tarımsal ürünlerde kendine yeterli olmayı hedeflemektedir (Güvenç ve Alan 1994b). Akdeniz'e kıyısı bulunan ve AB'nin sebze üretiminin \% 50-55' ini gerçekleştiren İtalya, İspanya, Fransa ve Yunanistan gibi ülkeler başta olmak üzere $A B$ önemli bir sebze üreticidir. Ancak $A B$ 'ye son 20-25 yılda Orta/kuzey Avrupa'dan çok sayıda ülkenin katılması ile özellikle sebze üretiminde kendine yeterlilik durumu azalmıştır. Günümüzde $A B$ genişlemeler sonucunda 500-550 bin nüfuslu bir pazar konumuna gelmiştir.

Türkiye'nin ekolojik şartları bir çok sebzenin yetiştiriciliğine uygundur. Son yıllarda girdi kullanımı ve yeni üretim teknolojileri nedeniyle toplam üretim miktarı önemli ölçüde artmıştır. Nitekim son yıllarda ülkemizin sebze üretimi 30-32 milyon tona ulaşmıştır. Türkiye’de üretilen sebzeler yurt içi taze ihtiyacını karşılamakta ve sanayiye hammadde sağlaması yanında ihracata da değerlendirilmektedir.

Türkiye sebze üretiminin iç pazar ihtiyacını fazlası ile karşıladığı, yeterliliğinin oldukça yüksek olduğu hatta fazla üretilen sebzenin pazarlanmasının önemli sorun olduğu belirtilmiştir (Güvenç ve Kaymak 2008). Bu nedenle sebze üreticileri için uzun yıllardan beri tam üyelik çalışmaları sürdürülen $\mathrm{AB}$ ülkeleri önemli bir pazar olabilir.

Ülkemizde sebze üretim ve iç ve diş pazarlarda değerlendirme durumu önceki çalışmalarda incelenmiştir (Alan ve Güvenç 1992; Güvenç ve Alan 1994 a, b; Kaymak ve ark. 2005; Güvenç ve Kaymak 2008; Güvenç ve Alan, R 1994b). Ayrıca, Türkiye ile o yıllardaki adıyla Avrupa Ekonomik Topluluğu (AET) Ülkelerinin sebzeciliği temel üretim 
özellikleri bakımından da karşılaştırılmıştır (Güvenç ve Alan 1994c.). Birliğin genişlemesi ve Türkiye sebze tarımındaki gelişmelerde dikkate alındığında Avrupa Birliği (AB) ve Türkiye sebzeciliğinin üretim ve yeterlilik durumunu belirlemek amacıyla bu çalışma yapılmıştır.

\section{AB ve Türkiye’nin sebzecilikte üretim durumu ve yeterlilikleri tespit edilmesi}

Bu çalışmada, Avrupa Birliği (AB) ve Türkiye’nin sebzecilikte üretim durumu ve yeterlilikleri tespit edilmesi amacıyla Birleşmiş Milletler Gıda ve Tarım Örgütü’nün (http://www.fao.org) istatistikleri esas alınmıştır. AB istatistiklerinde karpuz ve kavun sebze istatistiklerine dâhil edilmediğinden ülkemizle karşılaştırma için karpuz, kavun ve temel sebze şeklinde 3 adet sebze ürün grubu analize dâhil edilmiştir. Çalışmada FAO’nun ürün kodları (Item code) 1735 olan temel sebzeler (vegetables primary); 567 olan karpuz (Watermelons) ve 568 olan kavuna (Melons, other (inc.cantaloupes)) ait veriler kullanılmıştır. Böylece bu üç değerin toplanması ile ülkemiz istatistiklerine uyumlu sonuçlar elde edilmiştir. FAO istatistiklerinde diğer türlerle (gruplarla) birlikte verildiğinden bu kısımda orijinal İngilizceleri parantez içerisinde verilmiş̧ir. FAO verilerinde temel sebzeler (vegetables Primary) içerisinde enginar (artichoke), kuşkonmaz (asparagus), fasulye, (bean green), lahanalar (cabbages other brassicacae), havuç ve şalgam (carrots and turnips), karnabahar ve brokoli (cauliflowers and broccoli), biber (chillies and peppers, green), hiyar (cucumbers and gherkins), pirasa (leeks, other alliaceous vegetables), marul (lettuce and chicory), mantar (mushrooms and truffles), bamya (okra), kuru soğan (onions, dry), taze soğan (onions, shallots, green), bezelye (peas, green), kabak (pumpkins, squash and gourds), ispanak (spinach), domates (tomatoes) ve bakla (vegetables leguminous nes) incelenmektedir. Çalışmamızda FAO istatistiklerinde kavun (melons, other (inc.cantaloupes)) karpuz (watermelons) bu temel gruba dahil edilmiştir. Ayrıca çalışmada TUiK ile Tarım ve Orman Bakanlığı Bitkisel Üretim Genel Müdürlüğü’nün (BÜGEM) sebze üretimi ile ilgili verilerinden de yararlanılmıştır.

\section{Toplam Sebze Üretimi}

AB ülkeleri ve Türkiye'nin 1995' den günümüze olan toplam sebze üretimi Şekil 1 verilmiștir. AB'de 1995 'de 64.2 milyon ton olan sebze üretimi 2016 yllında $\% 8,0$ kadar artarak 69.2 milyon tona yükselmiştir. Türkiye'de ise 21,8 milyon ton olan üretim \% 38.1 artarak 30.1 milyon tona ulaşmıştır. Türkiye AB’nin sebze üretiminin 1995 yılında \%33’ü kadarına sahipken 2016 yılında bu oran artarak \% 43’üne yükselmiştir. Türkiye sebze üretimini daha da artırlabilme potansiyeline sahiptir.

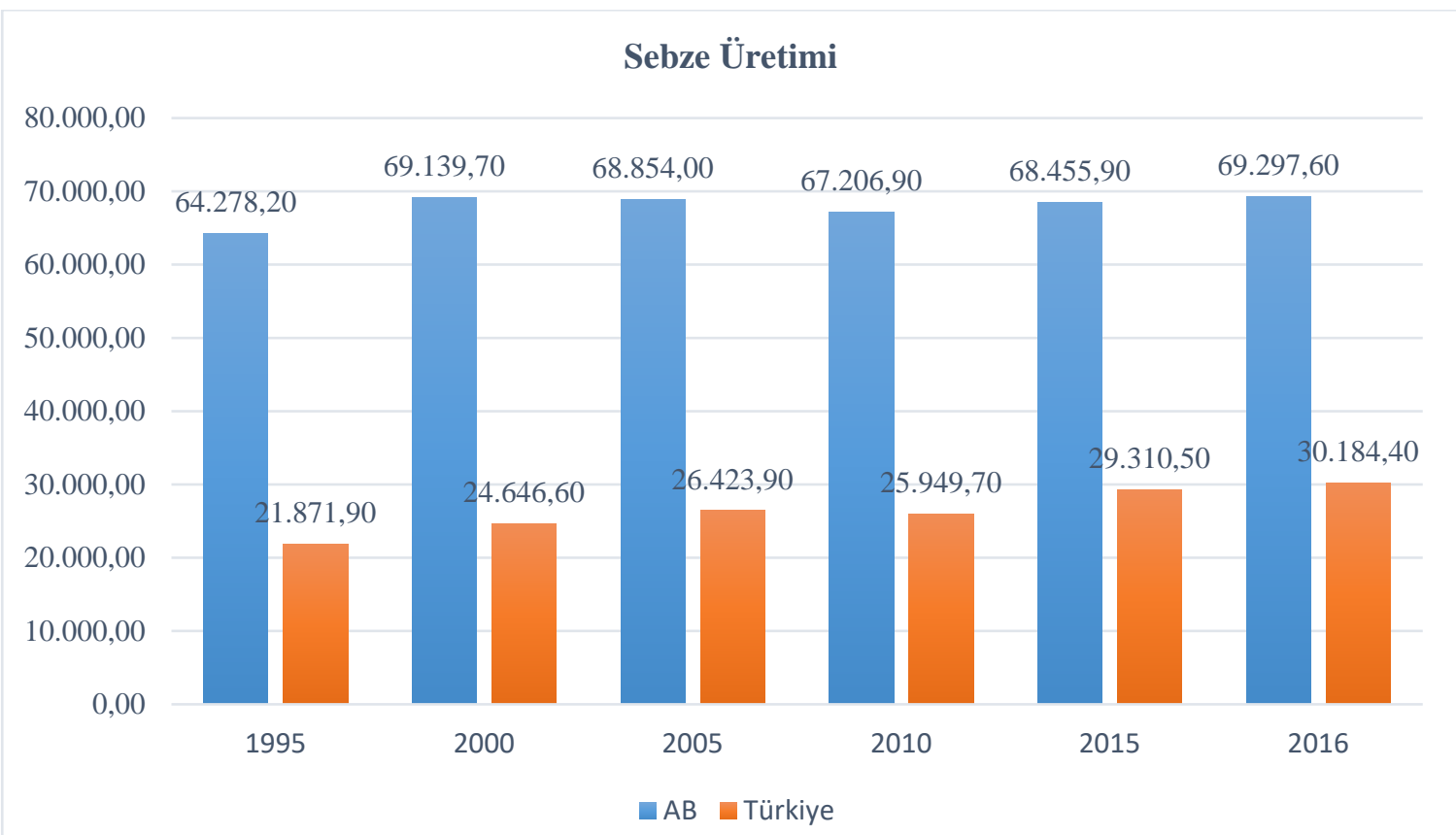

Şekil 1. AB ülkeleri ve Türkiye'nin Toplam Sebze Üretimi (1000 Ton/Y1l). Kaynak: http://www.fao.org/faostat Türkiye ve AB’de Sebze Üretiminin Türlere Göre Dağılımı

Türkiye'de sebze üretiminin \% 82.5'ni meyvesi yenilen sebzeler oluşturmakta olup diğer sebze grupları ise daha düşük paya sahiptir (Çizelge 1). Sebze türlerine göre baktığımızda ise domates, biber, patlıcan, kavun ve karpuz yüksek oranda üretilen türler arasındadır (Çizelge 2). Toplam sebze üretiminin 12-13 milyon ton üretimi ile \%40-45'ini sadece domates oluşturmaktadır. Türkiye'nin toplam sebze üretiminin $\% 25$ kadarını da karpuz ve kavun üretimi oluşturmaktadır. 
Çizelge 1. Türkiye'de Toplam Sebze Üretimi ve Gruplara Dağılımı (Ton/Yı1).

\begin{tabular}{|c|c|c|c|c|c|}
\hline Sebze Grubu & 2016 & $\%$ & 2017 & $\%$ & Değişim $^{(1)}(\%)$ \\
\hline $\begin{array}{l}\text { Yumru ve kökleri } \\
\text { yenen Sebzeler }\end{array}$ & 3399810 & 11.2 & 3425820 & 11.1 & 0.8 \\
\hline $\begin{array}{l}\text { Meyvesi yenilen } \\
\text { sebzeler }\end{array}$ & 24955248 & 82.5 & 25430915 & 82.5 & 1.9 \\
\hline Baklagil $^{(3)}$ sebzeleri & 892260 & 2.9 & 884798 & 2.9 & -0.9 \\
\hline $\begin{array}{l}\text { Yaprağı yenilen } \\
\text { Sebzeler }\end{array}$ & 1621237 & 5.4 & 1662145 & 5.4 & 2.5 \\
\hline Diğer sebzeler ${ }^{(2)}$ & 290602 & 0.9 & 306689 & 0.9 & 5.5 \\
\hline Toplam & 30266897 & 100 & 30825569 & 100 & 1,8 \\
\hline
\end{tabular}

Kaynak: www.tuik.gov.tr'den; (1): 2016'ya göre 2017'deki artış ve azalıșı göstermektedir.; (2): Karnabahar, brokoli ve mantar toplamını göstermektedir; (3)Baklagil sebzeler meyvesi yenilen sebzeler içinde de değerlendirilmiş ama yüzdeye dahil edilmemiştir.

AB ülkelerinde 17.9 milyon ton ile en fazla üretilen sebze domatestir (Çizelge 3). AB sebze üretiminde serin iklim sebzelerinin (lahanagiller, havuç, marul gibi) payı Türkiye'ninkinden daha yüksektir (Çizelge 1 ve 3). Türkiye ile AET ülkelerinin (şimdiki ismi AB) 1988 ve 1999 yıllarına ait sebzecilik faaliyetlerinin incelendiği bir çalışmada (Güvenç ve Alan 1994c) sebze grupları ve türleri bakımından benzer bulgular elde edilmişti. AB ülkelerinde yaprak ve yumruları yenilen sebzeler; Türkiye'de ise meyvesi yenilen sebzeler üretimde daha fazla paya sahiptir.

Çizelge 2. Türkiye’de Üretilen Önemli Sebze Türlerinin Üretim Miktarları (Ton).

\begin{tabular}{|c|c|c|c|c|c|c|}
\hline Tür/Grup & 1995 & 2000 & 2005 & 2010 & 2015 & 2016 \\
\hline Enginar & 18000 & 24500 & 36000 & 29070 & 32701 & 36368 \\
\hline Kuşkonmaz & 15 & 12 & 12 & 254 & 68 & 145 \\
\hline Taze Fasulye & 460000 & 514000 & 555000 & 587967 & 640836 & 651094 \\
\hline Lahana ve diğer lahanagiller & 675000 & 725000 & 675900 & 693002 & 766675 & 785971 \\
\hline Havuç ve şalgam & 250900 & 236500 & 390300 & 534946 & 534988 & 554736 \\
\hline Karnabahar ve Brokoli & 80000 & 90000 & 125500 & 185072 & 226619 & 250330 \\
\hline Biber & 1080000 & 1480000 & 1829000 & 1986700 & 2191888 & 2457822 \\
\hline Hiyar & 1250000 & 1825000 & 1745000 & 1739191 & 1822636 & 1811681 \\
\hline Patlican & 750000 & 924000 & 930000 & 846998 & 805259 & 854049 \\
\hline Sarımsak (Taze+Kuru) & 104500 & 102000 & 109000 & 98170 & 119223 & 135148 \\
\hline Pirasa & 315000 & 308000 & 326000 & 244812 & 231678 & 227172 \\
\hline Marul & 249000 & 333000 & 424000 & 419298 & 447492 & 478442 \\
\hline Mantar & 2276 & 7000 & 17000 & 21559 & 39495 & 40272 \\
\hline Bamya & 23000 & 27500 & 36000 & 36748 & 30574 & 29529 \\
\hline Soğan (Kuru) & 2850000 & 2200000 & 2070000 & 1900000 & 1879189 & 2120581 \\
\hline Soğan (Taze) & 235000 & 228000 & 200000 & 165478 & 141691 & 134479 \\
\hline Bezelye & 49000 & 48000 & 122000 & 90191 & 112638 & 112643 \\
\hline Kabak & 348000 & 332000 & 379500 & 430402 & 408286 & 489999 \\
\hline Ispanak & 180000 & 205000 & 238000 & 218291 & 208403 & 210999 \\
\hline String beans & 36000 & 41000 & 54000 & 70614 & 79704 & 82690 \\
\hline Domates & 7250000 & 8890000 & 10050000 & 10052000 & 12615000 & 12600000 \\
\hline Taze sebzeler & 216230 & 256150 & 267750 & 263158 & 302500 & 302000 \\
\hline Bakla & 50000 & 45000 & 49000 & 41929 & 35359 & 35081 \\
\hline Kavun & 1800000 & 1865000 & 1825000 & 1611600 & 1719600 & 1854300 \\
\hline Karpuz & 3600000 & 3940000 & 3970000 & 3683100 & 3918000 & 3928900 \\
\hline
\end{tabular}

Kaynak: http://www.fao.org/faostat/en/\#data/QC 
Çizelge 3. Avrupa Birliği Ülkelerinde Üretilen Önemli Sebze Türlerinin Üretim Miktarları (Ton).

\begin{tabular}{|c|c|c|c|c|c|c|}
\hline Tür/Grup & 1995 & 2000 & 2005 & 2010 & 2015 & 2016 \\
\hline Enginar & 863862 & 903767 & 753756 & 725911 & 665549 & 615407 \\
\hline Kuşkonmaz & 228973 & 232962 & 257221 & 263673 & 292203 & 300575 \\
\hline Taze Fasulye & 913261 & 941938 & 914708 & 736855 & 734035 & 741827 \\
\hline Lahana ve diğer lahanagiller & 6945523 & 6605073 & 5810196 & 5203693 & 4720604 & 4959456 \\
\hline Havuç ve şalgam & 4559501 & 5593453 & 5988708 & 5500456 & 5271292 & 5859202 \\
\hline Karnabahar ve Brokoli & 2333655 & 2399943 & 2278181 & 2326250 & 2258518 & 2275907 \\
\hline Biber & 2154311 & 2315052 & 2409095 & 2211332 & 2439445 & 2387065 \\
\hline Hiyar & 2587597 & 2466975 & 2570863 & 2775664 & 2804151 & 2917314 \\
\hline Patlican & 682251 & 781789 & 781151 & 802907 & 850014 & 851477 \\
\hline Sarımsak(Taze+Kuru) & 414958 & 370294 & 295539 & 282115 & 313152 & 302074 \\
\hline Pirasa & 945724 & 831608 & 835986 & 863226 & 787078 & 754409 \\
\hline Marul & 3296270 & 3383719 & 3393467 & 2910750 & 2760070 & 2842821 \\
\hline Taze misır & 678201 & 1420149 & 1758088 & 2122931 & 2481298 & 2668137 \\
\hline Mantar & 933193 & 1030582 & 1051064 & 1706632 & 1830148 & 1906833 \\
\hline Bamya & 1200 & 1270 & 1788 & 1608 & 1050 & 1832 \\
\hline Kuru soğan & 4853452 & 5255936 & 5432273 & 5643721 & 6326407 & 6513158 \\
\hline Taze soğan & 508150 & 528183 & 537265 & 622899 & 602636 & 729703 \\
\hline Bezelye & 1463217 & 1256148 & 1012679 & 1097320 & 965896 & 961155 \\
\hline Kabaklar & 1159397 & 1344853 & 1125024 & 1355563 & 1433804 & 1631099 \\
\hline Ispanak & 492766 & 532751 & 566176 & 477398 & 562450 & 533537 \\
\hline String beans & 375777 & 398891 & 424501 & 400923 & 351052 & 357267 \\
\hline Domates & 15044008 & 17875628 & 18425613 & 16888865 & 18256263 & 17916137 \\
\hline Taze sebzeler & 7472602 & 7428247 & 6775047 & 7054334 & 6803750 & 6498731 \\
\hline Bakla & 248406 & 244272 & 219363 & 256786 & 274172 & 178706 \\
\hline Kavun & 2483300 & 2150500 & 2291000 & 2184400 & 1800500 & 1739200 \\
\hline Karpuz & 2638700 & 2846200 & 2945300 & 2790700 & 2870400 & 2854600 \\
\hline
\end{tabular}

Kaynak: http://www.fao.org/faostat/en/\#data/QC

\section{AB’de Sebze Üretiminin Ülkelere Dağılımı}

Çizelge 4. Avrupa Birliği Ülkelerinde Toplam Sebze Üretimi (1000 ton/2016).

\begin{tabular}{lrrrrr}
\hline Ülke & Sebze & Kavun & Karpuz & Toplam & $\%$ \\
\hline AB-28 & 64703 & 1739 & 2854 & 69296 & 100 \\
Almanya & 3744 & - & - & 3744 & 5.4 \\
Avusturya & 616 & - & 0.6 & 616.6 & 0.9 \\
Belçika & 1996 & - & - & 1996 & 2.9 \\
Birleşik Krallık & 2503 & - & - & 2503 & 3.6 \\
Bulgaristan & 597 & - & 85.6 & 682.6 & 1.0 \\
Çekya & 239 & - & - & 239 & 0.3 \\
Danimarka & 315 & - & - & 315 & 0.5 \\
Estonya & 63 & - & - & 63 & 0.1 \\
Finlandiya & 275 & - & - & 275 & 0.4 \\
Fransa & 4911 & 251.5 & 16.8 & 5179 & 7.5 \\
Hirvatistan & 1469 & - & 22.9 & 1492 & 2.2 \\
Hollanda & 4986 & 1.6 & - & 4988 & 7.2 \\
İrlanda & 245 & - & - & 245 & 0.4 \\
İspanya & 12324 & 661.8 & - & 12986 & 18.7 \\
İsveç & 370 & - & - & 370 & 0.5 \\
İtalya & 13603 & 632.3 & 534,0 & 14769 & 21.3 \\
Kibris & 85 & 15.3 & 20.8 & 121 & 0.2 \\
Letonya & 182 & - & - & 182 & 0.3 \\
Litvanya & 193 & & - & 193 & 0.3 \\
Lüksemburg & 2.6 & & - & 2,6 & 0.0 \\
Macaristan & 1375 & 15.2 & 195,5 & 1586 & 2.3 \\
Malta & 76 & 2.5 & 3.2 & 82 & 0.1 \\
Polonya & 5876 & & - & 5876 & 8.5 \\
Portekiz & 2493 & 45.0 & 31.7 & 2570 & 3.7 \\
Romanya & 2899 & 59.0 & 418.5 & 3377 & 4.9 \\
Slovakya & 115 & 0.4 & 2.5 & 118 & 0.2 \\
Slovenya & 101 & - & 969.3 & 1070 & 1.5 \\
Yunanistan & 3040 & 54.1 & 553.2 & 3647 & 5.3 \\
\hline Kana & & & & &
\end{tabular}

Kaynak: http://www.fao.org/faostat/en/\#data/QC 
AB ülkelerinde 2000 yılından sonraki veriler dikkate alındığında yıllar arasında önemli farklılıklar olmaksızın 69 milyon ton civarında bir sebze üretimi yapılmaktadır (Çizelge 4). Bu üretimin \% 65-70’i 7 üye ülkede gerçekleştirilmektedir (Çizelge 4). Bu ülkeler İtalya (\% 21.3), İspanya (\% 18.7), Polonya (\% 8.5), Fransa (\% 7.5), Hollanda (\% 7.2), Almanya (\% 5.4) ve Yunanistan’dır (\% 5.3). Sadece Akdeniz'e kıyısı bulunan ülkelere ait veriler dikkate alınsa bile bu grup ülkelerde sebze üretiminin \% 50 kadarı gerçekleştirilmektedir.

\section{Yeterlilik Durumu}

Ülkemizde sebze üretimi yıllara bağlı olarak düzenli olarak artmaktadır. Nitekim 2017 verilerine göre 30 milyon tondan fazla sebze üretimi gerçekleştirilmiştir (Şekil 1). Ülkemiz nüfusunun 80,8 milyon (TÜIK) olduğu dikkate alındığında yılda fert başına 374 kg kadar sebze üretilmektedir (Çizelge 5). Gıda ve Orman Bakanlığı Bitkisel Üretim Genel Müdürlüğü Türkiye'nin sebze üretiminde kendine yeterliliğini \%120 olarak bildirmektedir (BUGEM 2017). Kişi başına sebze üretimi $135 \mathrm{~kg}$ olan AB ülkelerinin ise pazarlama zincirindeki kayıplar ve net sebze ihtiyacı dikkate alındığında (Güvenç ve Kaymak, 2008) düşük olduğunu söylemek mümkündür.

\begin{tabular}{lcccl}
\multicolumn{5}{l}{ Çizelge.5 Türkiye ve AB'de Sebzelerde Yeterlilik } \\
\hline Ülke & Toplam & $\begin{array}{l}\text { Nüfus } \\
(1000)\end{array}$ & $\begin{array}{l}\text { Üretim } \\
\text { (Kg/Fert) }\end{array}$ & Yeterlilik \\
\hline Türkiye & 30183 & 80800 & 374 & Yüksek \\
AB-28 & 69296 & 51805 & 135 & Düşük \\
\hline
\end{tabular}

Kaynak: FAO ve TUIKK veri tabanlarından yararlanarak hazırlanmıştır

\section{Sonuç ve Öneriler}

Türkiye hâlihazırda yüksek miktarda sebze üretimi yanında sebze üretimini daha da artıracak potansiyele sahiptir. Bu haliyle bile AB'ye tam üye olması halinde birliğin en büyük sebze üretici konumuna gelecektir. Türkiye’nin sebze üretiminde AB'deki başlıca rakipleri İspanya, İtalya ve Fransa'dır.

Türkiye Tarımı; ölçek yapısı, teknolojik gelişmenin düzeyi, kamusal hizmet kurumlarının niteliği, çiftçilerin sosyokültürel özellikleri, uygulanan desteklerin niteliği ve niceliği, tarımsal-kırsal altyapının tamamlanma düzeyi, üretilen tarım ürünlerinin kalite standartları ve insan sağlığına etkileri açısından AB’ye tam üye ülkelerden çok farklı koşullara sahiptir (Uysal ve Erdoğan 2008). Tarımın alt bir kolu olarak sebzecilik sektöründe de benzer özellikler söz konusudur. Türkiye ürün maliyetleri ve kalite hususunda gerekli tedbirleri aldığında taze sebzelerde veya dondurulmuş ve işlenmiş sebze ürünlerinde $\mathrm{AB}$ pazarlarında söz sahibi olabilir.

\section{Kaynaklar}

AKİB (2017). Akdeniz Yaş Meyve Sebze İhracatçıları Birliği Çalışma Raporu 2017, Yenişehir-Mersin, S:22.

Alan, R. ve Güvenç İ (1992). Türkiye’nin Sebze İhracatına Genel Bir Bakış. Tarımda Kaynak Dergisi, 1(1-2): 15-17. Bashimov G (2016). Türkiye' nin domates ihracat performansı ve rekabet gücü. (bk. http://dergipark.gov.tr/download/article-file/311449).

Bojnec, S, Fertő I (2006). Does comparative advantages in agro-food trade matter for multifunctional rural development: the case of Hungary and Slovenia. Journal of Central European Agriculture, 7(3), 583-586.

BÜGEM (2017). https://www.tarim.gov.tr/BUGEM/Menu/9/Veriler. Erişim Tarihi: 03.04.2018

Erkan B, Arpacı BB, Yaralı F, Güvenç İ (2015). Türkiye’nin sebze ihracatında karşılaştırmalı üstünlükleri. KSÜ Doğa Bil. Derg., 18(4): 70-76.

Erkan B (2012a). Türkiye'nin Geleneksel İhraç Tarım Ürünlerinde Uzmanlaşma Düzeyi. Sosyal ve Beşeri Bilimler Dergisi, 4(1):75-83.

Erkan B (2012b). BRIC Ülkeleri ve Türkiye’nin ihracat uzmanlaşma ve rekabet düzeylerinin karşılaştırmalı analizi. Ekonomik ve Sosyal Araştırmalar Dergisi, 8 (1):101-131.

FAO (2018). http://www.fao.org/faostat/en/\#data/QC. Erişim Tarihi: 11.05.2018

Fertő I. Hubbard LJ (2001). Regional Comparative Advantage and Competitiveness in Hungarian AgriFood Sectors. 77th EAAE Seminar / NJF Seminar No. 325, August 17-18, Helsinki, p: 1-13.

Güvenç I, Kaymak HC (2008). Türkiye’de sebze üretimi ve tüketimindeki değişme, gereksinim ve projeksiyon. Alinteri, 15 (B): 40-45.

Güvenç İ, Alan R (994a). Türkiye’nin Orta Doğu ülkelerine sebze ihracatı. Atatürk Üniversitesi Ziraat Fakültesi Dergisi, 25, (2):269-274

Güvenç İ, Alan R (1994b). Türkiye'nin Avrupa Topluluğu ülkelerine sebze ihracatı. Atatürk Üniversitesi Ziraat Fakültesi Dergisi, 25, (1) :94-99. 
Güvenç İ, Alan R (1994c9. Türkiye ile Avrupa Topluluğu ülkeleri sebzeciliğinin temel üretim özellikleri bakımından karşılaştırılması. Atatürk Üniversitesi Ziraat Fakültesi Dergisi, 25, (4) :627-633.

Güvenç İ (2017). Sebzecilik: Temel Bilgiler, Muhafaza ve Yetiştiricilik. Nobel Yayınları, Ankara, S: 288.

Hajiyev NO (2004). Study of Azerbaijan's Current and Potential Comparative Advantage. Center of Economic Reforms Ministry of Economic Development-UNDP Azerbaijan, Baku, p:8

Kaymak HC, Güvenç İ, Dursun A (2005). Türkiye’de sebze tarımının mevcut durumu, önemli bazı gelişmeler ve çözüm önerileri. Atatürk Üniversitesi Ziraat Fakültesi Dergisi, 36, (2): 221-228.

TUIK (2018). http://www.tuik.gov.tr/PreTablo.do?alt_id=1001. Erişim Tarihi: 01.05.2018.

Uysal ÖK, Erdoğan O (2008). Türkiye ve Avrupa Birliği Tarım Sektörlerinin Karşılaştırılması. 2. Ulusal İktisat Kongresi / 20-22 Şubat 2008 / DEÜ İIBF İktisat Bölümü / İzmir -Türkiye. 